\title{
Introducing an Innovative Spatial Interpolation Methodology for Precipitation
}

\author{
Mohammad Zare ${ }^{1}$, Guy Schumann ${ }^{2}$, Norman Teferle ${ }^{3}$, and Laura Giustarini² \\ ${ }^{1}$ RSS Hydro \\ ${ }^{2}$ RSS-Hydro \\ ${ }^{3}$ University of Luxembourg
}

May 6, 2021

\begin{abstract}
The development of precise and simple spatial interpolation methods to estimate rainfall data in ungauged locations provides not only better understating and new insights into the predictive hydrological models but also improves the accuracy of these models. In this Scientific Briefing a new approach for rainfall spatial interpolation in Luxembourgian case study has been introduced. The method used here is based on a Fuzzy C-Means (FCM) clustering method. In the normal FCM procedure, there are a lot of available data and each data point belongs to a cluster, with a membership degree [0 1], i.e. the data points clustered in an iterative process, whereas in our methodology the center of clusters has been determined first and then random data will be generated around cluster centers. Therefore, this approach is called inverse FCM (i-FCM) from here on. In order to calibrate and validate the new spatial interpolation method four rain gauges in Luxembourg ( 3 for calibration and one for validation) with 10 years of measured data were used and consequently the rainfall for ungauged locations were estimated. The results show that the i-FCM method can be applied with acceptable accuracy in validation rain gauge with values for R2 and RMSE of 0.92 and $12 \mathrm{~mm}$, respectively, on monthly time scale and 0.84 and $1.8 \mathrm{~mm}$ on daily time scale.
\end{abstract}

\section{Hosted file}

iFCM.pdf available at https://authorea.com/users/412283/articles/521019-introducing-aninnovative-spatial-interpolation-methodology-for-precipitation 


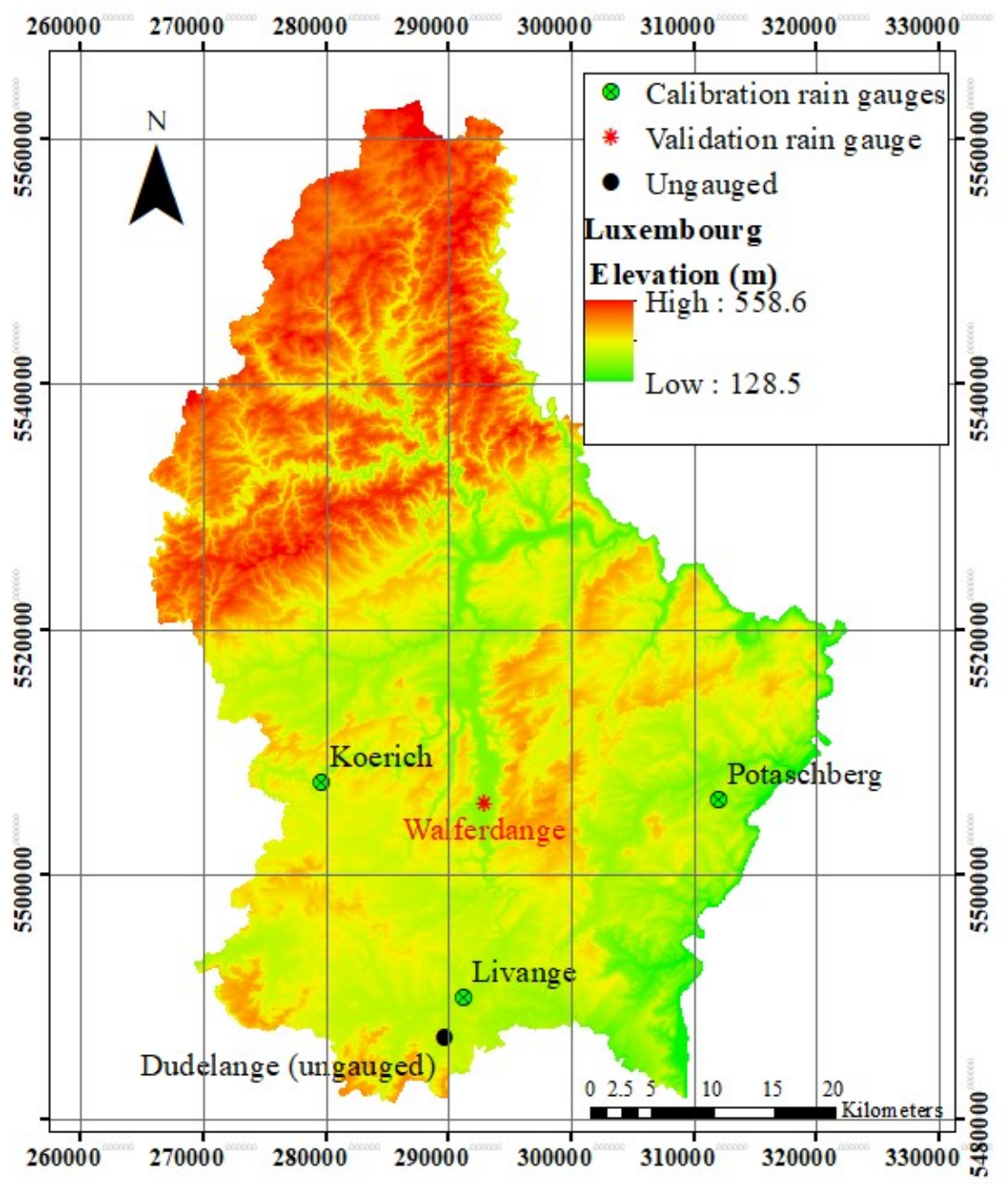



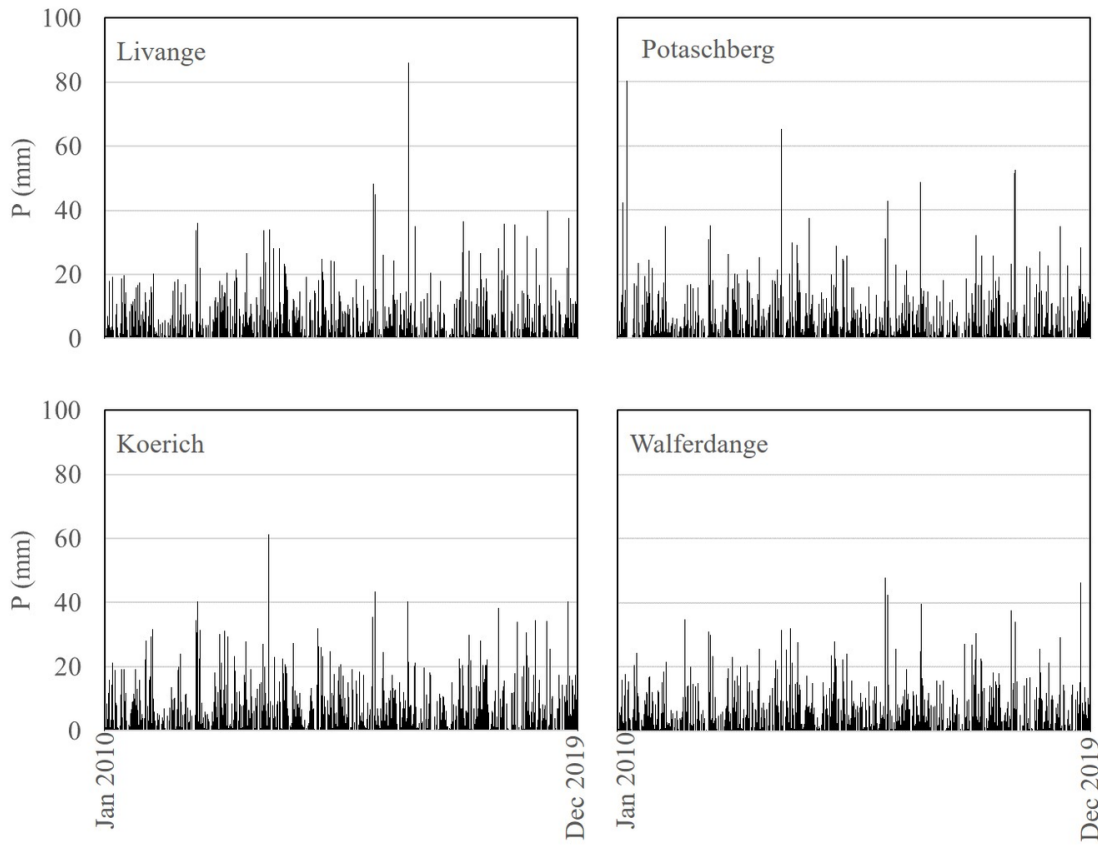

Walferdange

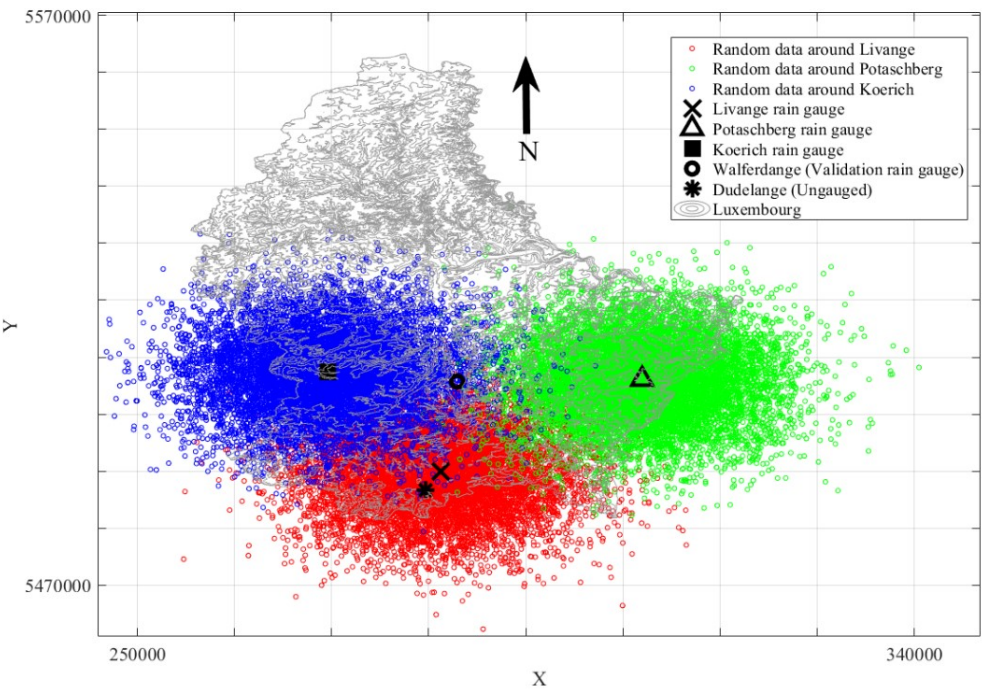



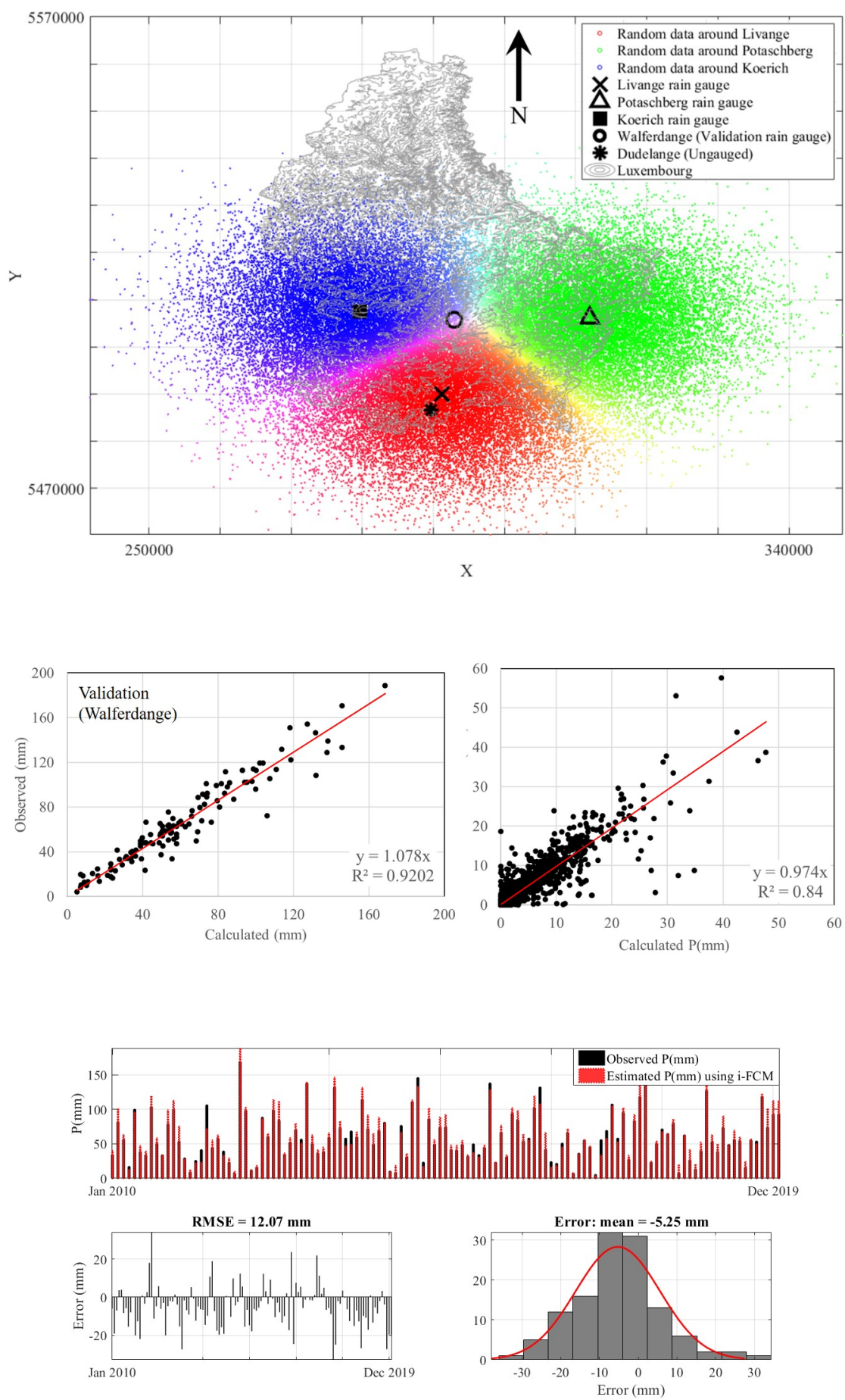

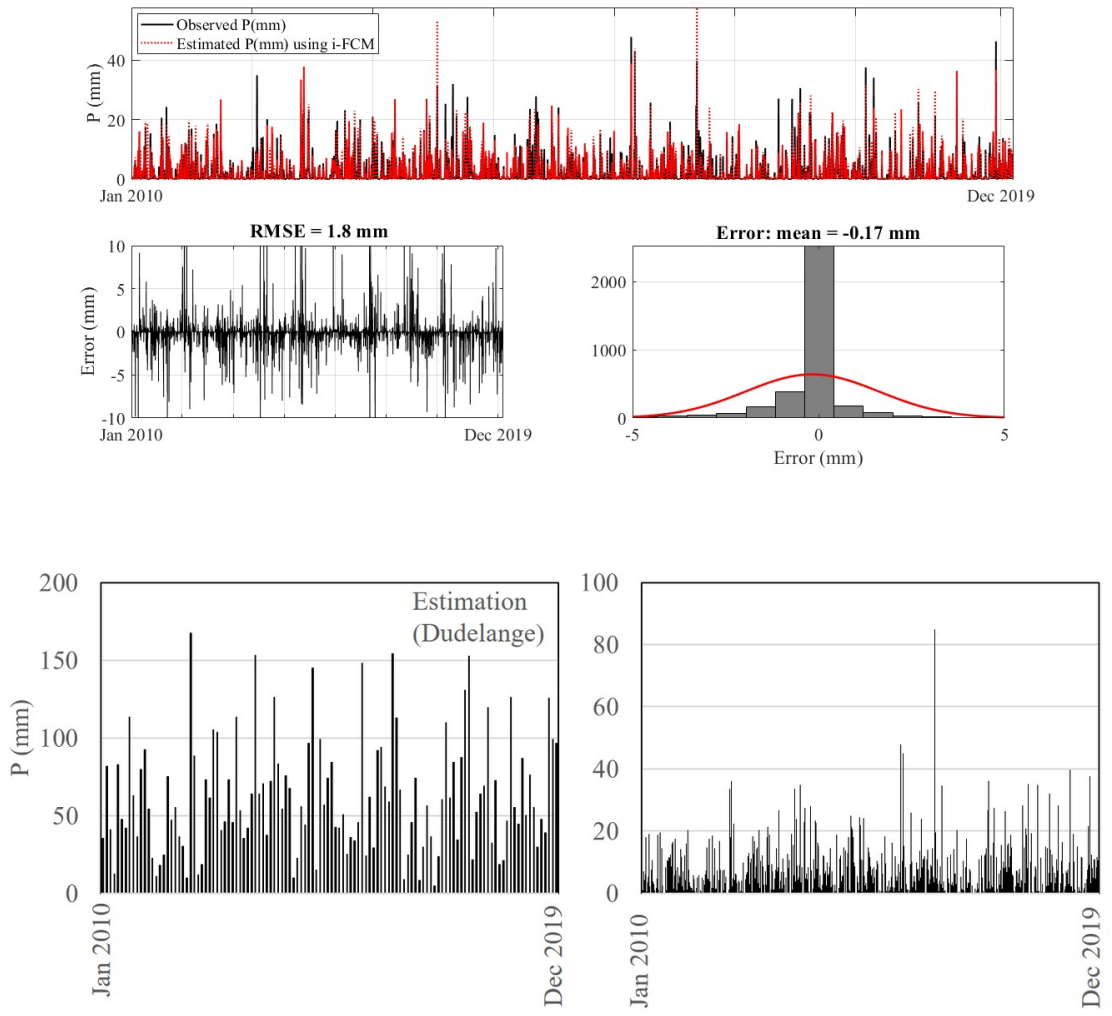